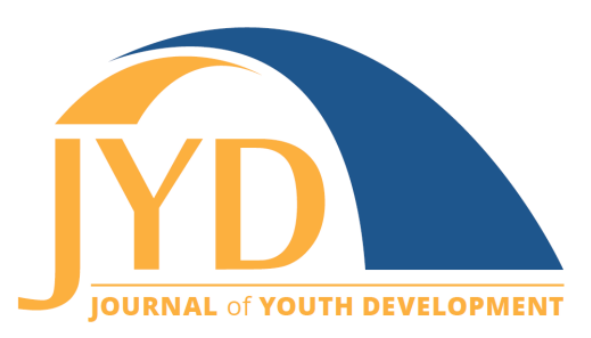

http://jyd.pitt.edu/ | Vol. 16 Issue 4 DOI 10.5195/jyd.2021.1170 | ISSN 2325-4017 (online)

\title{
Youth Programs Are Important Spaces for Emotional Learning
}

\author{
Reed W. Larson \\ University of Illinois at Urbana-Champaign \\ larsonr@illinois.edu \\ Natalie Rusk \\ Massachusetts Institute of Technology
}

\begin{abstract}
Emotional skills are now widely recognized to be essential skills for young people to survive and thrive across all aspects of their lives. Teens become able to develop powerful new skills for understanding and managing their emotions. They also are able to learn skills for using the valuable functions of emotions. But this learning isn't automatic; it depends on experience. In this commentary, we highlight key elements of youth programs that make them important contexts for youth's active engagement in emotional learning. We present examples from research on how program staff facilitate youth development of skills to manage and use emotions. We conclude with suggestions on practices and policies that support emotional learning.
\end{abstract}

Key words: emotional learning, youth programs, staff practices

Adults often view teenagers as "emotional"-as subject to powerful biological drives and states beyond their control. Though often exaggerated, there is a strand of truth in this stereotype. Research finds that across the day the average teen experiences somewhat wider emotional swings with greater emotional intensity than the average adult (Bailen et al., 2019; Larson \& Sheeber, 2008). What is often overlooked, however, is that adolescence is an important period for emotional learning (National Academies of Science, Engineering, and Medicine, 2019). Teens become able to develop powerful new skills for understanding and managing their emotions. They also are able to learn powerful skills for using the valuable functions of emotions, including using them for motivation, assessing situations, and developing positive relationships (Izard et al., 2008). But this learning isn't automatic; it depends on experience. In this commentary we examine how teens in youth programs learn these skills.

(cc) EY New articles in this journal are licensed under a Creative Commons Attribution 4.0 License. This journal is published by the University Library System, University of Pittsburgh and is cosponsored by the University of Pittsburgh Press. The Journal of Youth Development is the official peer-reviewed publication of the National Association of Extension 4-H Youth Development Professionals and the National AfterSchool Association. 


\section{Important Spaces for Emotional Learning}

Emotional skills are now widely recognized to be essential skills for young people to survive and thrive. Evidence from multiple fields shows that development of these skills is important to every domain of life: school, work, family, relationships, community engagement, and mental health (National Research Council, 2012). Emotional learning is also integral to the development of other $21^{\text {st }}$ century skills, such as problem solving and teamwork. However, knowledge is limited on the learning processes through which youth learn these skills.

Another pressing issue right now is: Where can teens develop emotional knowledge and skills? Some policy makers are looking to schools to take this on. But can we expect already overburdened middle and high schools to make the changes needed to focus on teenagers' emotional learning? Further, evidence suggests that teens cannot easily be taught socialemotional skills with a top-down curriculum. They develop these skills most effectively through direct experiences (Yeager, 2017). Youth programs, we believe, are better designed to facilitate this experiential learning. They create a safe and supportive environment for youth-driven learning processes (Eccles \& Gootman, 2002). Participants develop trusting relationships with staff, within which they feel comfortable and empowered to experiment and learn about emotions (Griffith \& Larson, 2016). Authentic youth-driven activities, collaborative projects, and supportive relationships with peers and staff all make programs rich contexts for emotional learning. Indeed, in survey research, youth report more emotion learning experiences in programs than in school classrooms (Hansen et al., 2003; Larson et al., 2006). The important role of programs in supporting emotional learning deserves greater recognition.

Our goal here is to share what we have learned about emotional development in programs, with hopes of inspiring broader discussion among program staff and administrators, policy makers, and researchers. We use examples from our studies to illuminate both what youth can and do learn about emotions in effective programs and how they learn it. The commentary is based on interviews our team has conducted over 20 years with many hundreds of ethnically and racially diverse youth in programs and with more than 100 frontline program staff. ${ }^{1}$ Most

\footnotetext{
${ }^{1}$ In our studies, we interviewed youth and staff from many dozens of programs about the processes of social and emotional learning. These programs served ethnically and racially diverse youth (mostly Latina/o, African American/Black, \& White), ages 14-18, from low- to middle-income families. Because we wanted to learn about processes of positive development, we chose programs that we call "higher quality" (i.e., high retention of youth and staff, youth-centered focus).
} 


\section{Important Spaces for Emotional Learning}

were interviewed on multiple occasions across a program offering, so that we could understand the unfolding of youth's learning experiences and staff practices over time.

In this commentary, we first describe some of the key elements of programs that make them favorable contexts for youth's active engagement in emotional learning. Second, we present highlights from our findings on how programs facilitate youth development of skills to selfregulate strong negative emotions, particularly intense anxiety. Third, we describe findings on a topic that is rarely mentioned: how teens learn to use emotions in ways that build $21^{\text {st }}$ century skills, such as directed motivation and relationship skills. At the end, we conclude with suggestions on practices and policies that support emotional learning.

Before starting we want to make one point about emotions and one about the data on which this commentary is based. First, in the not-too-distant past, many people thought of emotions as separate from cognition, as raw animal drives. Psychologists now recognize that emotions and emotional learning incorporate extensive learned "cognitive" knowledge (Izard et al., 2011), including cultural knowledge (Mesquita et al., 2016). Thought and emotion are integrated. Second, we want to acknowledge that while our qualitative studies provide rich "experiencenear" systematic insights on what happens inside programs, it is theory development not testing. But we think this is a good starting point for building knowledge that is aimed at supporting youth learning and staff practices.

\section{Youth Programs as Favorable Contexts for Emotional Learning}

Emotions are hard to learn about. They are subjective, intangible, and can seem unreal. Yet they are real, and powerful! They can seize control over thoughts and influence actions. Emotions can also be awkward to talk about; they can feel wrong or embarrassing. Talking with others about emotions, however, can be invaluable to learning about them-to discovering that different emotions have (somewhat) consistent properties and dynamics between and within people. Youth programs provide an environment in which this talk is supported. Youth's projects and staff practices also facilitate emotional learning.

\section{Program Culture}

The program cultures of the diverse youth programs we studied supported youth's active engagement in discussing emotions and learning about them through experience. Staff 
communicated that emotions were an important part of human life and they nurtured a shared ethos of care and concern, so youth felt safe talking about them. Staff modeled and facilitated discussion of ongoing emotions. Youth embraced this culture and learned from talking about both their own and others' experiences. Some programs had a shared vocabulary they used for talking about emotions and helping youth learn strategies for managing them (e.g., "stepping back," resetting, healthy vs unhealthy expressions of anger; Smith et al., 2016)

At the Emerson High School theater program, for example, the staff communicated in numerous ways that the program was a place where emotions were named, respected, and could be discussed (Larson \& Brown, 2007). One member said that the director, Ann, "would just make you know it was alright to feel frustrated or feel however you felt." This mindset was shared among peers. Another said: "It's such a family type group that you can just open up your heart to anyone, even if you don't know them well, and you should let them do the same." We found that many strategies for dealing with stress, frustration, and stage fright were part of the program culture. They were passed between youth to adapt, try out, and learn.

\section{Projects}

In many programs for teens, the main activity is work on projects (e.g., creating a film, producing a play, or organizing a community event); and the emotions youth experience as they collaborate on these projects provide rich opportunities for experiential learning about emotions. Because youth are highly invested in their projects (Larson, McGovern \& Orson, 2020), when their work goes well, they experience positive emotions, such as excitement, joy, and pride, and they learn about the emotional episodes associated with these. Likewise, encountering challenges and obstacles in their work can create negative emotions, such as frustration, anger, and, occasionally, a spiral of anxiety and self-doubt. Across projects, youth experience many of these emotional episodes, allowing for cumulative learning about the dynamics of different emotions and strategies for managing and using them (Rusk et al., 2013).

\section{Staff Practices}

Staff in programs we have studied supported youth-driven emotional learning in many ways. They earned youth's trust, so youth felt safe going to them when setbacks caused distress: "I can ask questions without feeling embarrassed" and "If I get it wrong, he won't get mad at me." (Griffith \& Larson, 2016). Staff provided emotion coaching, serving as "a guide on the side" who supported youth's emotional autonomy, while helping them learn to deal with anger 


\section{Important Spaces for Emotional Learning}

or frustration (Smith et al., 2016). This included: helping youth calm intense distress, learn signals that they were experiencing an emotion, and understand what made them upset. Staff helped foster emotional reflection and coached youth on strategies they could use to manage emotions (Rusk et al., 2013). Youth also described leaders as valuable models of emotional skills. Several Emerson members said that observing how gracefully Ann handled difficult conflict situations helped them decide that they could be a teacher (Walker \& Larson, 2006). We provide further examples of staff roles in supporting emotional learning in the next sections.

\section{Learning to Regulate Emotions}

People often think about emotions as problems that need to be controlled. Indeed, at any age, strong negative emotions, like anger and fear, can be problematic. They create high physical arousal, often accompanied by tunnel vision, impaired reasoning, helplessness, and negative thoughts toward self and others (Maloney et al., 2014). Repeated negative emotions can lead to avoidance and unhealthy forms of coping. So, it is vital that young people develop skills for managing them. Adolescence is an important period for this because teens gain capacities for learning new, effective methods for emotional regulation, such as learning to reevaluate (or "reappraise") the cues or events that triggered an emotion (Somerville, 2016).

\section{How Youth Learn Self-Regulation}

Youth programs, we found, are settings in which many young people develop self-regulation skills. Because youth are typically highly invested in their projects and their group, they are motivated to figure out how to manage emotions that interfere. For example, Ryan discovered that, "[when] you get frustrated you block out a lot of ideas." So, he experimented and developed strategies to calm himself down. Liliana was deeply invested in community events her group planned; she described learning to control her temper so it would not disrupt their collaboration. Many youth reported learning that when someone expressed their anger at others, it becomes contagious. So, they developed ways to manage their anger.

In our studies, youth often mentioned roles that peers played in these learning processes. When they were upset, peers helped them cool down or distracted them. Peers also suggested useful strategies to regulate strong emotion and reappraise situations that triggered them (Orson et al., 2020; Rusk et al., 2013). Tamara described learning from a friend how to contain 
her anger at others: "Don't worry about what they're saying. Walk away, count to 10 , talk about something else."

Program staff support and facilitate this youth-driven emotional learning in multiple ways. For instance, when youth experienced overwhelming anxiety from project setbacks, staff helped them reframe their situation to make it manageable (e.g., adjusting their goals, trying a new approach; Orson \& Larson, 2021). In some cases, staff helped youth solve intransigent emotion-triggering problems. In one of these cases, a sequence of miscommunications created spiraling anger among three friends working together on a film; and they stopped speaking to each other. But a discussion facilitated by Lora, the adult leader, helped them talk through what each was feeling and figure out the causes of the cascading anger. This led to important emotional learning. Rosana described being surprised to discover that her peers "didn't mean to make me feel like that." She learned a profound lesson: "That it is really easy to interpret something wrong, and not realize how other people are interpreting your actions." Another said, "I learned that communication is the key to everything." Lora's diplomacy in organizing the meeting allowed youth to learn together how to break the spiral of anger and not be so quick to anger in the future.

\section{Learning to Manage Anxiety Attacks}

Let us share a fuller example that shows how staff can play a deep, skilled role facilitating youth's development of emotional self-regulation skills. We found that when a youth has an anxiety attack, positive engagement in activities often comes to a screeching stop. They experience an emotional spiral, in which they go from feeling overwhelmed to intensely anxious to feeling incompetent, helpless, and unmotivated (Larson, McGovern, \& Olson, 2020). Repeated experiences of extreme anxiety cause people to avoid that experience in the future, precluding their learning to manage their anxiety (Miloyan et al., 2016).

We wanted to know how program staff can help youth learn to regulate and control these spiraling anxiety episodes. Outward Bound (OB), a wilderness expedition program, was a good place to find answers because it challenges youth emotionally and physically, yet evaluation studies show that participation is related to decreased anxiety and increases on measures of emotional resilience and challenge-seeking (Ewert \& Sibthorp, 2014; Hattie et al., 1997). So, how do youth learn to regulate anxiety? To address this, we asked $30 \mathrm{OB}$ leaders to describe a case example of a youth who had an anxiety "meltdown" and where they had successfully helped the youth learn to overcome it. We obtained detailed accounts of youth's learning and 


\section{Important Spaces for Emotional Learning}

how the instructors facilitated it, a learning process that often took several days or weeks (Larson, Orson, \& McGovern, 2021).

Following an anxiety attack, teens are often embarrassed, defensive, and distrustful (Shirk, 2018). OB instructors responded to this by quietly sitting with the youth in a calm spot away from others. They helped youth de-escalate by reassuring them and being patient, respectful, and present with the youth.

As youth were ready, a next goal was helping them start to describe and make sense of what had happened to them. Many were distressed by how out of control they had felt. An instructor said one young person "didn't know why she was freaking out . . . and that was making her freak out even more." Rebecca and other instructors emphasized to youth that their emotions were "a normal response . . . All humans feel these feelings." Rebecca used open-ended questions so youth could process answers for themselves. Instructors validated youths' emotions, helped them accept ownership, and helped youth build their understanding of the predictable elements of their anxiety attacks (e.g., their causes and effects).

In follow-up conversations, instructors then facilitated youths' development of skills for preventing the spiral. They helped them identify bodily and mental cues that signaled that they were on the verge of an anxiety attack and try out strategies for stopping it. As youth mastered these strategies, instructors supported their planning ahead for future situations that might cause anxiety, for instance, by working together to prepare strategies to get through a demanding hike, redirect thoughts away from anxiety triggers, and rehearse how they can handle a difficult situation. An important finding was that facilitating youth's emotional learning involved a progression of steps, from building a youth-centered working alliance, to supporting youth's abilities to observe and reflect on their emotions, to strategy building.

These instructor practices helped youth develop skills to experience control over trigger situations and regulate anxiety attacks. As a result, $\mathrm{OB}$ instructors reported youth were able to take on new and more difficult challenges. We have seen similar transformational learning in other programs where youth learn to overcome other emotional challenges, such as performance anxiety in theater programs and spiraling anger between peers across different types of programs. 


\section{Learning to Use Emotions}

Human life would be bleak if we experienced emotions only as problems to be regulated. They are much more. Emotions have many powerful positive functions. They can help us work toward valued goals, form positive relationships, and add meaning to our lives, among other things (Barrett et al., 2016). To use emotions effectively requires developing knowledge and skills for utilizing the properties of different emotions as catalysts to achieve goals. Youth in the programs we studied learned to use emotions in many ways. In this section we focus on four ways: using emotions for motivation; to evaluate work; to build strong collaborative relationships; and to develop moral reasoning.

\section{Using Emotions for Motivation}

Research shows that emotions can energize and direct motivation to achieve desired goals (Izard et al., 2008; Sands et al., 2016). Youth in programs learn to use the motivation from excitement, pride, compassion-even anger and worry-to help motivate their work toward their project goals. Cody at Emerson theater described learning to use the "triumph" she experienced in mastering a dance as "a big source of motivation" that she carried over to work on dances she was struggling with. A youth on a sports team said: "I was mad because I knew we could get to the playoff if we do better. I started practicing so I could get better and release my frustration." Program staff sometimes helped youth channel strong emotions into their work (Smith et al., 2016).

In interviews with youth in 12 programs about their experiences with pride, we discovered that this emotion was a frequent long-term motivator. Youth reported learning to harness their current and anticipated pride as motivation for their work (e.g., on a film, a garden, event planning). Anticipated pride and satisfaction in the work's outcome were especially helpful to keep them going when they were discouraged by setbacks (Larson, Rusk, \& Izenstark, 2021). The experience of pride and passion in their work also motivated youth to find ways to reduce unconstructive behaviors, like procrastinating, making excuses, and lingering on mistakes. They learned "you need to put in 100\% to feel your best about your work." Emotions do not just provide raw motivation; they can provide directed motivation that helps one do good work. 


\section{Important Spaces for Emotional Learning}

\section{Using Emotions for Evaluation}

An important function of emotions is for evaluation of ongoing experiences. Joy, disappointment, and mixed emotions convey perceptions and appraisals of "whether something is good for me or not" (Suri \& Gross, 2016, p. 453). This includes appraisals of whether one is making progress toward goals. Positive and negative emotional signals are often based on memories of how similar past experiences had turned out (Baumeister et al., 2007). For youth in programs, these emotional evaluations provide valuable internal feedback when working on projects. The evaluations signaled by emotions, however, are not always reliable, especially if you are a novice to a field (Clore \& Schiller, 2016). Feelings of elation or imminent failure among youth in our studies could be misleading. But they were gaining experience and knowledge to improve the reliability of their emotions for evaluation. For example:

Delphia "hated" how the eyes of a person she was painting looked, despite several tries. Each time she penciled in how she wanted the eyes on the graffiti mural. But when she spray-painted over the lines, she disliked the result. Then Desiree, a staff member, explained to her that murals were not meant to be viewed from up close, and suggested that Delphia walk back 10 feet and look from there. From that distance Delphia was able to see that the eyes were just a small part of the larger picture; and Delphia saw (and felt) that overall, the mural looked promising.

Desiree helped Delphia gain a new perspective for her emotional appraisals, a perspective aligned with the practices of graffiti art. Delphia was able to move forward using emotions based on this new perspective.

Youth doing projects learn criteria, standards, and assessment methods within the domains of their work, and these shape the emotional evaluations they feel. This was apparent in our study of youth's experiences with pride (Larson, Rusk, \& Izenstark, 2021). We discovered that youth were cautious about whether their work really merited feeling proud or satisfied. We asked them what (if anything) made them proud of their work, and they cited evidence and rationales for deserving it: They had finished on time and exceeded their goals; they had grown and harvested vegetables for the community; the audience had cheered after their video; children they were teaching had shared what they learned with their families. Sometimes their pride was grounded in standards of quality they had learned within a field (e.g., theater, videography). They also cited reasons for their pride that were generalizable beyond their field. They learned to feel proud because they had worked long and hard, persevered, or had overcome difficult challenges. Staff helped them recognize that it was not just the outcome, but the effort that 
they put into their work that was pride-worthy-a valuable sensibility for future work of any kind (Dweck, 2006).

In short, youth were learning about "the feel" of doing good work. For example: that setbacks are frustrating but an expected part of any complex project; that satisfaction with your work often comes in slow steps but the effort is worth it; and that excitement, anxiety, and pride can all provide helpful information, but you need to learn to interpret, reflect and discriminate what information is useful feedback. Emotional evaluations add meaning to experiences (King \& Hicks, 2021). For youth in programs, they add meaning to their work and accomplishments.

\section{Building Positive Collaborative Relationships}

Emotions, of course, also have social functions, most centrally facilitating human bonds. At the simplest, the ongoing exchange of positive emotions among people (e.g., happiness, caring, gratitude) create and sustain strong relationships (Fischer \& Manstead, 2016). Exchanges of positive emotions also can be a catalyst for successful collaboration.

But there are important emotional-social skills that people must learn to use in these exchanges to build sturdy collaborations. Orson (2021) identified emotional barriers teens encounter to forming positive collaborative peer bonds. For example, teens in an unfamiliar situation often start from an untrusting, self-defensive posture; or they may fear being judged or humiliated for revealing their ideas or personal vulnerabilities. Many experienced program staff have expertise in helping youth transcend these barriers. They are skilled at organizing activities and environments that help youth learn to build emotional trust and safety with each other (Larson, 2007; Smith et al., 2016). They also introduce language teens can use to develop relationships of mutual concern and respect for each other's emotions (Orson, 2021).

This staff support-coupled with youths' working together on projects-provides rich opportunities for youth to learn skills for emotionally positive collaborations:

At Media Masters youth started out working separately on computers when learning to use editing software. But staff encouraged them to go to each other for help. Joaquin was very wary at first because: "The only people I know are mean." But he started giving help and asking for help from Victoria, and they both discovered how rewarding it was to trust each other, exchange information, and experience joy solving problems together. 


\section{Important Spaces for Emotional Learning}

Across programs, youth learned to see the benefits of peer collaborations and became motivated to try to overcome the emotional challenges they can present. They developed skills for communicating ideas, emotional reactions, and personal needs. They learned strategies for adapting to different people, like turn-taking, active listening, and respectful disagreement (Smith et al., 2016). A youth, who had been intolerant of peers who disagreed with her, learned: "Everybody's just gotta give and everybody's got to hold back just a little" (Larson et al., 2005, p. 173).

Youth also learned to exchange positive emotions and mutual help as part of their daily work. Interactions became infused with comradery, smiles, shared humor, and "high fives." They described learning to "say positive stuff and have positive attitudes" and to be compassionate with each other (Orson et al., 2020, p. 14; Larson et al., 2019). These reciprocal exchanges of positive emotions and actions serve as a glue that holds relationships together (Fischer \& Manstead, 2016).

Of course, collaborative relationships can have emotional ups and downs. Group members can have misunderstandings. Youth encounter peers whom they find hard to work with (e.g., "slackers," "know-it-alls"). But in effective programs they learn strategies to resolve issues that arise (Perry, 2015). Smith et al. (2016) found that when youth participants did something hurtful, they typically apologized, were forgiven, and tried to do better. Social emotions, such as guilt and embarrassment, can make youth aware of the social consequences of their actions and motivate them to change how they treat others. When youth are invested in shared goals, they learn skills to manage the dynamics of diverse interpersonal situations and to use both positive and negative emotions as feedback and motivation to facilitate positive collaborative relationships (Larson \& Brown, 2007; Perry, 2015).

\section{Using Emotions for Development of Moral Reasoning}

During adolescence, ethical development goes beyond learning rules of right and wrong. It requires learning to apply ethical principles (e.g., fairness, justice, rights, concern for human welfare) to complex real-world situations (Killen \& Cooley, 2014; Turiel, 2016). This learning is enhanced when young people grapple with real-life moral situations in discussions with peers (Snarey \& Samuelson, 2014). In programs we studied, youth often grappled with complex issues together in ways that expanded their moral perspectives and reasoning (Larson, Walker, \& McGovern, 2020). 


\section{Important Spaces for Emotional Learning}

Emotions often played an important role in these learning processes. An example was shared by Juanita, an adult leader from a program that served Latina/o youth in a rural, mostly White town. She described how a youth named Antonio walked into a group meeting, upset by the hostility and rejection he had just experienced when he tried to join a school band. Juanita noticed how Antonio's experiences of prejudice hit a nerve with other youth. In the discussion that followed, youth shared their own experiences of prejudice for the first time. Juanita explained, "It started to tap into some other nerves and that whole experience of prejudice. There was a lot of anger about it. We just got it out on the table." Juanita said youth's strong emotions were the catalyst for applying ethical principles of fairness and justice to their situation. Working together, they identified structures in the town that marginalized Latina/o youth and their families, which reinforced the group's moral commitment to supporting these families.

Emotions played a similar catalytic role in discussions of moral issues in other programs. Baumeister and colleagues (2007) describe how emotions can serve important functions by directing attention to the causes of an emotion and then stimulating reflection, evaluation, and learning. This is what we observed in programs. In some cases, these discussions were initiated by staff, as part of a planned activity or in response to a provocative guest speaker or film. But youth also learned to use emotions in this way to stimulate discussions of moral concerns from their own experiences (Larson et al., 2012; Smith et al., 2016).

Issues of diversity, equity, and moral inclusion were a frequent topic of deliberation in the programs we studied, and the processes had similar elements. Discussions often began with youth going around the group providing reactions to an issue or recounting relevant personal experiences. In different programs, youth shared accounts of their experiences from diverse ethnic, racial, and cultural backgrounds, gender identities, and sexual orientations. As in Antonio's program, this included raw feelings of anger, fear, and hurt; but also, absurdity and laughter. Through hearing these accounts, youth report that peers' lives became vivid, authentic, and morally significant. They empathized with each other's hardships, broke through typecast images, and described, "discovering the humanity" in others (Watkins et al., 2007). As a youth in a theater program said:

You learn to understand [others' views] and, even if it disagrees with your own belief, even if you're not adopting it as your own truth, you still learn to work with it and understand it . . . people are so different from you, but they become part of you. 
These conversations led youth to expand the inclusiveness of their ethical perspectives to accommodate different experiences and value positions. Program staff played supportive roles, including sustaining rules for respectful conversation and affirming youth's emotions and their deliberative processes (Smith et al., 2016).

In addition to expanded ethical perspectives, youth learned to apply these processes of moral reasoning to complex real-world situations. They learned to use emotions-their own and others-as catalysts for talking with others, listening, questioning, and developing moral positions. What youth in programs learn through these discussions is not that emotions provide indisputable information about right or wrong. Rather, it is that emotions signal the need for reflection on values, including considering different viewpoints.

\section{Conclusions and Suggestions}

Emotional development in programs is a really large topic, and we have just scratched the surface. We cannot summarize the wide variety and important nuances of what youth in our studies learned about emotions through their experiences in programs. Learning outcomes ranged from knowledge of emotional dynamics to strategies for regulating, managing, and using emotions. Youth learned to apply these skills to their work, relationships, and understanding people who were different than themselves.

To simplify, we want to highlight two key, tangible components of youth's emotional learning that cut across domains. First, an important function of emotions for humans is as signals about situations: They warn of threats, provide feedback on progress toward goals, and signal us about matters of right and wrong. Teens in our research appeared to increase their abilities to interpret these signals. This included learning to assess the information emotions provide, to think critically about criteria for feeling proud, and to be cautious about how anger at others can stem from misunderstanding. Second, youth were learning to use emotions as catalysts for positive functions: for directed motivation in long-term work and for building collaborative relationships. They learned to tap into emotions as catalysts for collective deliberation on moral issues. In our research on pride, we have also seen how youth use emotions to help identify work they find meaningful.

The different types of learning processes that youth and staff describe are also wide-ranging. Youth in our studies learned about emotions through experimenting and figuring things out, 


\section{Important Spaces for Emotional Learning}

modeling and coaching by staff, discussion with peers, and internalizing language and norms from the program culture. In nearly all cases, youth learned from direct experience and observation and saw themselves as agents of their emotional development. Based on our findings on these processes, we offer the following suggestions on how emotional learning can be supported:

\section{Program Design and Culture}

1. Design programs to provide environments of trust, safety, and mutual caring.

2. Cultivate a program culture where youth are respected and supported as active agents of their learning, including their emotional learning. Recognize how they learn through feeling, noticing, describing, managing, and reflecting.

3. Provide opportunities for youth to talk about emotions and share strategies for managing and using emotions.

4. Structure programs to engage teens in meaningful projects. These provide authentic experiences of learning to manage and use emotions in work youth care about.

5. Recognize that people from different cultural backgrounds may have different experiences, values, and strategies for handling emotions.

\section{Staff Practices}

6. Acknowledge youth's emotions and be ready to talk about them.

7. Encourage youth to:

- View emotions as signals to pay attention to and interpret.

- Examine the causes and effects of emotions.

- Learn from peers; support each other's emotional learning.

8. Help youth view emotional situations from different perspectives.

9. When appropriate, offer strategies that youth might try for managing emotions.

10. Encourage youth to reflect on the usefulness of emotions, for example, for motivating work, evaluating situations, cultivating relationships, and ethical learning.

11. Support youth as they develop standards and criteria for feeling satisfaction or pride in their work.

12. Recognize that staff are valuable emotional models for youth.

\section{Policy, Priorities, and Funding}

13. Provide resources and support for staff to develop their skills for facilitating youth's emotional learning. 
14. Arrange regular time and support for staff members to process and discuss unfolding emotion-related issues in the program (e.g., issues in youth projects, youth's reactions to a situation, and staff's self-care needs.)

15. Encourage and invest in research on emotional learning in adolescence, especially applied research on staff practices and youth's emotional learning in programs.

These suggestions, of course, should be adapted by programs and staff for the youth they serve, in response to youth's needs, interests, cultural backgrounds and lived experiences (see also Smith et al., 2016).

The development of emotional skills is important for all young people. They are critically important for youth's future work, relationships, well-being, and contributions to society. Youth programs stand out as unique, invaluable contexts for youth to build these skills. In our research, we have seen the transformative role that high-quality programs and experienced staff play in facilitating adolescents' emotional learning. Much can be done to support this learning more fully for participants in all youth development programs.

\section{Acknowledgements}

Many thanks to The William T. Grant Foundation and the Character Lab for generously funding this research. We appreciate the program staff and instructors whose contributions made this study possible. Thank you also to the recent contributors to our research on emotions: Carolyn Orson, Gina McGovern, and Kate Walker.

Correspondence concerning this article should be addressed to Reed W. Larson, Department of Human Development and Family Studies, University of Illinois at Urbana-Champaign, $904 \mathrm{~W}$. Nevada St. MC 081, Urbana, IL 61801. Email: larsonr@illinois.edu.

\section{References}

Bailen, N. H., Green, L. M., \& Thompson, R. J. (2019). Understanding emotion in adolescents: A review of emotional frequency, Intensity, instability, and clarity. Emotion Review, 11(1), 63-73. https://doi.org/10.1177/1754073918768878

Barrett, L. F., Lewis, M., \& Haviland-Jones, J. M. (Eds.). (2016). Handbook of emotions (4 ${ }^{\text {th }}$ ed.). Guilford. 
Baumeister, R. F., Vohs, K. D., DeWall, C. N., \& Zhang, L. (2007). How emotion shapes behavior: Feedback, anticipation, and reflection, rather than direct causation. Personality and Social Psychology Review, 11, 167-203. https://doi.org/10.1177/1088868307301033

Clore, G. L., \& Schiller, A. J. (2016). New light on the affect-cognition connection. In L. F. Barrett, M. Lewis, \& J. M. Haviland-Jones (Eds.). Handbook of emotions, (4 ${ }^{\text {th }}$ ed., pp. 532-546). Guilford.

Dweck, C. S. (2006). Mindset: The new psychology of success. Random House.

Eccles, J. S., \& Gootman, J. A. (Eds.). (2002). Community programs to promote youth development. National Academy Press.

Ewert, A. W., \& Sibthorp, J. (2014). Outdoor adventure education: Foundations, theory, and research. Human Kinetics.

Fischer, A. H., \& Manstead, A. S. R. (2016). Social functions of emotion and emotion regulation. In L. Feldman Barrett, M. Lewis \& J. M. Haviland-Jones (Eds.), Handbook of emotions (4 ${ }^{\text {th }}$ ed., pp. 424-439). Guilford.

Griffith, A. N., \& Larson, R. W. (2016). Why trust matters: How confidence in leaders transforms what adolescents gain from youth programs. Journal of Research on Adolescence, 26, 790-804. https://doi.org/10.1111/jora.12230

Hansen, D. M., Larson, R. W., \& Dworkin, J. B. (2003). What adolescents learn in organized youth activities: A survey of self-reported developmental experiences. Journal of Research on Adolescence, 13(1), 25-55. https://doi.org/10.1111/1532-7795.1301006

Hattie, J., Marsh, H. W., Neill, J. T., \& Richards, G. E. (1997). Adventure education and outward bound: Out-of-class experiences that make a lasting difference. Review of Educational Research, 671), 43-87. https://doi.org/10.3102/00346543067001043

Izard, C., Stark, K., Trentacosta, C., \& Schultz, D. (2008). Beyond emotion regulation: Emotion utilization and adaptive functioning. Child Development Perspectives, 2, 156-163. https://doi.org/10.1111/j.1750-8606.2008.00058.x

Izard, C. E., Woodburn, E. M., Finlon, K. J., Krauthamer-Ewing, E. S., Grossman, S. R., \& Seidenfeld, A. (2011). Emotion knowledge, emotion utilization, and emotion regulation. Emotion Review, 3(1), 44-52. https://doi.org/10.1177/1754073910380972

Killen, M., \& Cooley, S. (2014). Morality, exclusion, \& prejudice. In M. Killen \& J. Smetana (Eds.), Handbook of moral development ( $2^{\text {nd }}$ ed., pp. 340-360). Psychology Press. http://dx.doi.org/10 $.4324 / 9780203581957 . c h 16$

King, L. A., \& Hicks, J. A. (2021). The science of meaning in life. Annual Review of Psychology, 72, 561584. https://doi.org/10.1146/annurev-psych-072420-122921 
Larson, R. W. (2007). From 'I' to 'We': Development of the capacity for teamwork in youth programs. In Approaches to Positive Youth Development (pp. 277-292). SAGE.

\section{https://doi.org/10.4135/9781446213803.n15}

Larson, R. W., \& Brown, J. R. (2007). Emotional development in adolescence: What can be learned from a high school theater program? Child Development, 78, 1083-1099.

https://doi.org/10.1111/j.1467-8624.2007.01054.x

Larson, R. W., Hansen, D., \& Moneta, G. (2006). Differing profiles of developmental experiences across types of organized youth activities. Developmental Psychology, 42, 849-863. https://doi.org/10.1037/0012-1649.42.5.849

Larson, R. W., Hansen, D., \& Walker, K. (2005). Everybody's gotta give: Development of initiative and teamwork within a youth program. In J. L. Mahoney, R. W. Larson, \& J. S. Eccles (Eds.), Organized activities as contexts of development (pp. 159-183). Lawrence Erlbaum Associates.

Larson, R. W., Jensen, L., Kang, H., Griffith, A., \& Rompala, V. (2012). Peer groups as a crucible of positive value development in a global world. In G. Trommsdorff \& X. Chen (Eds.) Values, Religion, and Culture in Adolescent Development (pp. 164-187). Cambridge University Press.

Larson, R. W., McGovern, G., \& Orson, C. (2020). Youth development programs: Supporting selfmotivation in project-based learning. In K. A. Renninger \& S. E. Hidi (Eds.), Cambridge handbook of motivation and learning (pp. 111-138). Cambridge University Press.

\section{https://doi.org/10.1017/9781316823279.007}

Larson, R. W., Orson, C., \& McGovern (2021). Responding to teenagers' emotional meltdowns: How Outward Bound instructors facilitate development of anxiety management skills. Submitted manuscript.

Larson, R. W., Raffaelli, M., Guzman, S., Salusky, I., Orson, C. N., \& Kenzer, A. (2019). The important (but neglected) developmental value of roles: Findings from youth programs. Developmental psychology, 55(5), 1019. https://doi.org/10.1037/dev0000674

Larson, R. W., Rusk, N., \& Izenstark, D. (2021). How youth develop authentic pride through collaborative projects. Manuscript in preparation.

Larson, R. W., \& Sheeber, L. (2008). The daily emotional experience of adolescents. In N. Allen \& L. Sheeber (Eds.), Adolescent emotional development and the emergence of depressive disorders (pp. 11-32). Cambridge University Press.

Larson, R. W., Walker, K., \& McGovern, G. (2020). Youth programs as contexts for development of moral judgment and agency. In: L A. Jensen (Ed.). Handbook of moral development: An interdisciplinary perspective (pp. 552-569). Oxford Press. https://doi.org/10.1093/oxfordhb/9780190676049.013.3 
Maloney, E. A., Sattizahn, J. R., \& Beilock, S. L. (2014). Anxiety and cognition. Wiley Interdisciplinary Reviews: Cognitive Science, 5(4), 403-411. https://doi.org/10.1002/wcs.1299

Mesquita, B., Boiger, M., \& De Leersnyder, J. (2016). The cultural construction of emotions. Current Opinion in Psychology, 8, 31-36. https://doi.org/10.1016/j.copsyc.2015.09.015

Miloyan, B., Bulley, A., \& Suddendorf, T. (2016). Episodic foresight and anxiety: Proximate and ultimate perspectives. British Journal of Clinical Psychology, 55(1), 4-22. https://doi.org/10.1111/bjc.12080

National Academies of Sciences, Engineering, and Medicine (2019). The promise of adolescence: Realizing opportunity for all youth. The National Academies Press. https://doi.org/10.17226/25388

National Research Council (2012) Education for life and work: Developing transferable knowledge and skills in the $21^{\text {st }}$ century. The National Academies Press. https://doi.org/10.17226/13398

Orson, C. N. (2021). Instructor strategies of facilitating the development of positive group culture in Outward Bound [Doctoral dissertation, University of Illinois at Urbana-Champaign].

Orson, C. N., \& Larson, R. W. (2021). Helping teens overcome anxiety episodes in project work: The power of reframing. Journal of Adolescent Research, 36(2), 127-153. https://doi.org/10.1177/0743558420913480

Orson, C. N., McGovern, G., \& Larson, R. W. (2020). How challenges and peers contribute to socialemotional learning in outdoor adventure education programs. Journal of Adolescence, 81, 7-18. https://doi.org/10.1016/j.adolescence.2020.02.014

Perry, S. C. (2015). How teens learn teamwork: Agentic and constructive peer processes [Doctoral dissertation, University of Illinois at Urbana-Champaign].

Rusk, N., Larson, R. W., Raffaelli, M., Walker, K., Washington, L., Gutierrez, V., Kang, H., Tran, S., \& Perry, S. C. (2013). Positive youth development in organized programs: How teens learn to manage emotions. In C. Proctor \& P. Linley (Eds.), Research, applications, and interventions for children and adolescents (pp. 247-261). Springer. https://doi.org/10.1007/978-94-007-6398$\underline{215}$

Sands, M., Ngo, N., \& Isaacowitz, D. M. (2016). The interplay of motivation and emotion: View from adulthood and old age. In L. Feldman Barrett, M. Lewis \& J. M. Haviland-Jones (Eds.), Handbook of emotions ( $4^{\text {th }}$ ed., pp. 436-349). Guilford.

Shirk, S. R. (2018). Therapy and relational elements. In Child and adolescent psychotherapy: Components of evidence-based treatments for youth and their parents (pp. 319-335). Cambridge University Press. https://doi.org/10.1017/9781316717615.021 
Smith, C., McGovern, G., Larson, R. W., Hillaker, B., \& Peck, S. C. (2016). Preparing youth to thrive: Promising practices for social \& emotional learning. David P. Weikart Center for Youth Program Quality at the Forum for Youth Investment.

Snarey, J., \& Samuelson, P. L. (2014). Lawrence Kohlberg's revolutionary ideas: Moral education in the cognitive-developmental tradition. In L. Nucci, D. Narvaez, \& T. Krettenauer (Eds.), Handbook of moral and character education ( $2^{\text {nd }}$ ed., pp. 61-83). Routledge. https://doi.org/10.4324/9780203114896.ch5

Somerville, L. H. (2016). Emotional development in adolescence. In L. Feldman Barrett, M. Lewis \& J. M. Haviland-Jones (Eds.), Handbook of emotions, (4th ed., pp. 350-362). Guilford.

Suri, G., \& Gross, J. J. (2016). Emotion regulation: A valuation perspective. In L. Feldman Barrett, M. Lewis \& J. M. Haviland-Jones (Eds.), Handbook of emotions, (4 ${ }^{\text {th }}$ ed., pp. 453-466). Guilford.

Turiel, E. (2016). Moral development. In R. M. Lerner (Ed.), Handbook of child psychology and developmental science (Vol. 1, pp. 484-522). Wiley.

Walker, K. C., \& Larson, R. W. (2006). Balancing the professional and the personal. In D. A. Blyth \& J. A. Walker (Eds.), New Directions for Youth Development, No. 112 (pp. 109-118). Jossey-Bass.

Watkins, N. D., Larson, R. W., \& Sullivan, P. J. (2007). Bridging intergroup difference in a community youth program. American Behavioral Scientist, 51(3), 380-402. https://doi.org/10.1177/0002764207306066

Yeager, D. S. (2017). Social and emotional learning programs for adolescents. The Future of Children, 271), 73-94. https://doi.org/10.1353/foc.2017.0004 